\title{
CALENDARIO DE FIESTAS PATRONALES DE LA CIUDAD DEL CUSCO COMO PRODUCTO TURÍSTICO CULTURAL
}

\author{
Calendar of 'patronal' religious festivals from the city of Cusco as a cultural tourist product \\ Luis Serrano Paucarmayta 1 , \\ ${ }^{1}$ Universidad Andina del Cusco, Cusco, Perú. \\ $\risingdotseq$ pcmayta@gmail.com
}

\begin{abstract}
Resumen
Las fiestas patronales se realizan durante todo el año en las parroquias de la ciudad del Cusco y, comprenden diversas expresiones culturales autóctonas, que conforman un atractivo cultural de gran potencial; sin embargo, no forman parte activa de la oferta turística, lo cual no permite promocionar ni diversificar el producto turístico. El objetivo de esta investigación fue describir y categorizar las características de las fiestas patronales de la ciudad del Cusco como producto turístico cultural en potencia. La muestra de estudio consideró 35 fiestas patronales del calendario festivo y el análisis de la información fue recolectado en la ficha de categorización del patrimonio inmaterial del Ministerio de Cultura. El tipo de investigación fue cualitativa, de nivel exploratorio/descriptivo y la metodología de investigación fue inductiva. El análisis demostró que las fiestas patronales del Cusco, al ser categorizadas como atractivo turístico cultural, permiten su incorporación a la oferta turística actual. Junto con ello, se recomendó la jerarquización y promoción turística de las festividades y la sensibilización y capacitación de las personas involucradas en dicha actividad turística.

Palabras clave: diversificación turística, producto turístico cultural, oferta turística cultural, fiesta patronal.
\end{abstract}

\begin{abstract}
Patronal festivities (religious festivals) are held throughout the year in all the parishes of the city of Cusco and include various native cultural expressions, which make up a cultural attraction of great potential; however, they are not form an active part of the tourist offer, which does not allow to promote or diversify the tourist product. The objective of this research was to describe and categorize the characteristics of the patron saint festivities of the city of Cusco as a potential cultural tourism product. The study sample was: 35 festivities of the festive calendar and the analysis of the information was collected in the categorization of the intangible heritage of the Ministry of Culture. The type of research was qualitative, exploratory / descriptive level and the research methodology was inductive. The analysis showed that the patron festivities of Cusco, when categorized as a cultural tourist attraction, allow its incorporation into the current tourist offer. Along with this, it was recommended the hierarchy and tourist promotion of the festivities and the awareness and training of the people involved in this tourism activity.

Keywords: tourist diversification, cultural tourism product, cultural tourist offer, patronal feast.
\end{abstract}

Citar como: Serrano, L. (2018). Calendario de fiestas patronales de la ciudad del Cusco como producto turístico cultural. Rev Yachay, 7(1),373380 .

Recibido: 16-09-2018; Aceptado 07-12-2018

\section{Introducción}

El turismo cultural ha experimentado mayor crecimiento en la últimas décadas por ofrecer un mercado con múltiples posibilidades de desarrollo y otorgar carácter novedoso a la actividad turística (Mallor, González-Gallarza Granizo, \& Fayos Gardó, 2013), ya que se ha diversificado atendiendo la creciente demanda de nuevas atracciones y medios para el descubrimiento del otro y el retorno a lo tradicional (Hiernaux, 2002). De esta forma, las grandes fiestas patronales en ciudades y pueblos de Latinoamérica, son un factor más que dinamiza la economía local y contribuye a la conservación del patrimonio cultural inmaterial (Martínez Cárdenas, 2013). Asimismo, son considerados atractivos turísticos dentro de la categoría de 'Herencia Cultural', según la Organización Mundial del Turismo (Navarro, 2015, p. 343), constituyendo un eje de atracción para el turismo.

Las políticas gubernamentales del Perú, indican que el patrimonio cultural inmaterial es una vía hacia el desarrollo sostenible a través de proyectos de emprendimiento cultural o de turismo, que busquen fortalecer la sensibilidad de los visitantes por las expresiones culturales y generen recursos para las comunidades ((MINCETUR), 2017). Amparados bajo esta directriz, las principales fiestas patronales del Perú se promocionan en 'guías turísticas', lo que da pie a la realización de proyectos de turismo cultural que promuevan la participación del

Rev. Yachay volumen (7) Número (1), enero-diciembre 2018 
turista en dichas celebraciones. Se sabe que el impacto turístico está asociado a una capacidad de carga que determina los costes y beneficios del turismo (Quintero Santos, 2004); y la experiencia turística aplicada a un atractivo de valor inmaterial ha sido poco explorada en el Perú (Chacón Cruz, 2014); (Urbina Chuyacama, 2015).

Las fiestas patronales, como expresión cultural del hombre andino, también fueron ampliamente estudiadas desde la etnografía (Huayhuaca Villasante, 1985), la construcción de identidades (Cánepa Koch, 1988), la ritualidad (Flores Ochoa, 1990), la resistencia cultural (De la Cadena, Marisol, Orin Starn, 2010) y el análisis mítico (Serrano Paucarmayta, 2018); constituyendo un vasto y complejo tema de investigación antropológica.

En la ciudad del Cusco, las festividades patronales abarcan gran parte del calendario festivo anual y comprenden numerosas manifestaciones de religiosidad popular que constituyen un potencial atractivo turístico cultural; sin embargo, en la actualidad, no forman parte activa de la oferta turística de la ciudad, lo cual no permite promocionar y diversificar el producto en sí. Empero, el problema puede ser resuelto categorizando dichas festividades de acuerdo al 'Manual del Patrimonio Cultural' del Mincetur (Ministerio de Comercio Exterior y Turismo) y generando las condiciones adecuadas para la promoción de este nuevo producto turístico; en la sección "Resultados" presentamos un listado mensual de 35 fiestas patronales que formarían parte de la oferta turística de la ciudad del Cusco.

El objetivo del presente estudio fue describir y categorizar las características de las fiestas patronales de la ciudad del Cusco como producto turístico cultural en potencia. Este trabajo surgió de la necesidad de diversificar la oferta cultural de la ciudad del Cusco hacia el turismo receptivo. La contribución que hizo la presente investigación fue presentar las fiestas patronales de nuestra localidad, como atractivos potenciales de turismo cultural.

Un $15 \%$ de turistas internacionales y un $23 \%$ de turistas nacionales vinieron motivados por la participación en festividades locales en la ciudad del Cusco en el año 2017. La tendencia estadística pronostica que el porcentaje seguirá en aumento (PROMPERÚ, 2018); puesto que dichas festividades se celebran durante todo el año en el Cusco, hemos considerado viable su incorporación a la oferta turística cultural de la ciudad, promoviendo su diversificación.

\section{Materiales y métodos}

La presente investigación fue de tipo exploratoria y descriptiva, el método inductivo se realizó bajo un diseño cualitativo. Las unidades de estudio fueron 35 fiestas patronales de la ciudad del Cusco. Del mismo modo, se utilizó como técnica la observación no-participante o indirecta y, el análisis de documentación escrita y digital. Los escenarios fueron las parroquias y distritos donde se realizan dichas fiestas patronales. Los instrumentos utilizados para la recolección de antecedentes y revisión bibliográfica fueron: plataformas multimedia, fichas de observación, el manual para la formulación del inventario de recursos turísticos a nivel nacional (Fase I: Categorización), guía, ficha de observación y, la ficha de categorización del patrimonio inmaterial. El análisis del contenido descriptivo sobre las características de las fiestas patronales como producto cultural, se realizó de acuerdo con el criterio del investigador y las pautas del Mincetur.

\section{Resultados}

Una de las más completas expresiones culturales inmateriales en la ciudad del Cusco es su fiesta patronal, constituyendo un conjunto pedagógico que comprende diversas manifestaciones culturales en un solo espacio y tiempo; constituyendo por sí mismas un atractivo turístico potencial. Estas celebraciones se engloban en la categoría «Acontecimientos programados», en el tipo «Fiestas», y en el subtipo «Fiestas patronales y religiosas», según el Mincetur. Actualmente, la página web de la institución (http://sigmincetur.mincetur.gob.pe/),no provee una lista actualizada que considere todas las fiestas patronales del Cusco; por lo que, se determinó en realizar la labor de categorización de las siguientes 35 fiestas patronales más importantes del Cusco, de acuerdo al «Manual para la formulación del inventario de recursos turísticos a nivel nacional del Mincetur» (por la extensión limitada del artículo, solo se presentarán los resultados del análisis general, más no las fichas de categorización):

Enero:

- Señor del Cabildo (Parroquia de Santa Ana)

- $\quad$ Niño de San Cristóbal (Parroquia de San Cristóbal)

- San Antonio Abad (Parroquia de San Cristóbal)

- Virgen de Belén (Parroquia de Belén)

- San Sebastián (Parroquia de San Sebastián) Febrero:

- Virgen Purificada (Parroquia de San Pedro)

- San Blas (Parroquia de San Blas) 
Marzo:

Carnavales (fiesta en todas las parroquias)

- $\quad$ San Juan de Dios (Parroquia de San Pedro)

Abril:

San José (Parroquia de Belén)

- Semana Santa (fiesta en todas las parroquias)

Mayo:

- $\quad$ Fiesta de la Cruz (fiesta en todas las parroquias)

- $\quad$ San Isidro Labrador (Parroquias de San Sebastián y La Almudena)

- $\quad$ Santísima Trinidad (Parroquia Matriz o Catedral)

Junio:

- $\quad$ Ciclo celebratorio del Corpus Christi (Parroquia Matriz o Catedral)

- $\quad$ San Pedro y la Virgen Purificada (Parroquia de San Pedro)

Julio:

- $\quad$ Virgen del Buen Suceso (Parroquia de San Blas)

- $\quad$ Virgen del Carmen (Parroquia de Santa Teresa, San Blas, Santa Ana, Santiago).

- Santiago Apóstol (Parroquia de Santiago)

- $\quad$ Santa Ana (Parroquia de Santa Ana)

Agosto:

- San Cristóbal (Parroquia de San Cristóbal)

- $\quad$ Virgen de la Asunción (Parroquia Matriz o Catedral)

Setiembre:

- $\quad$ Natividad de la Virgen (Parroquia de La Almudena)

- Señor de la Exaltación (Parroquia de San Cristóbal)

- San Jerónimo (Parroquia de San Jerónimo)

Octubre:

- Virgen del Rosario (templo de Santo Domingo)

- $\quad$ San Francisco (templo de San Francisco)

- Señor de Ecce Homo (Parroquia de San Sebastián)

- $\quad$ Señor de los Temblores (Parroquia Matriz o Catedral)

Noviembre:

- Todos los Santos (se celebra en el casco histórico y en los cementerios)

- San Martin de Porres (Parroquia de San Pedro y templo de Santo Domingo)

Diciembre:

- $\quad$ Santa Bárbara (Parroquia del Dulce Nombre de Jesús de Poroy)

- Inmaculada Concepción (Parroquia Matriz o Catedral)

- Santurantikuy (se celebra en la Plaza de Armas del Cusco)

- $\quad$ Navidad Chumbivilcana (se celebra en la Plaza de Armas del Cusco)

Durante el trabajo de campo realizado en dichas festividades, se observaron las siguientes dimensiones del patrimonio inmaterial que son de interés turístico cultural:

a) Actos litúrgicos católicos

E1 77,9\% de los peruanos son católicos (Correo, 2017), por lo que los actos y rituales litúrgicos católicos en el Perú, aún se mantienen en constante reproducción ya que expresan vínculos afectivos y sociales. Los actos rituales católicos más importantes son los novenarios, la misa de fiesta y las procesiones que se realizan por las calles de la parroquia o distrito en el que se celebran. La comitiva está encabezada por danzas típicas, mayordomos y fieles que organizaron la fiesta, la imagen conducida en andas y banda de músicos. Una de las características más resaltantes de una típica procesión de fiesta patronal cusqueña es su carácter festivo. Del mismo modo, las imágenes pueden salir en procesión hasta en tres oportunidades visitando distintos sectores de su parroquia, generando interacción directa con los pobladores y asistentes. 


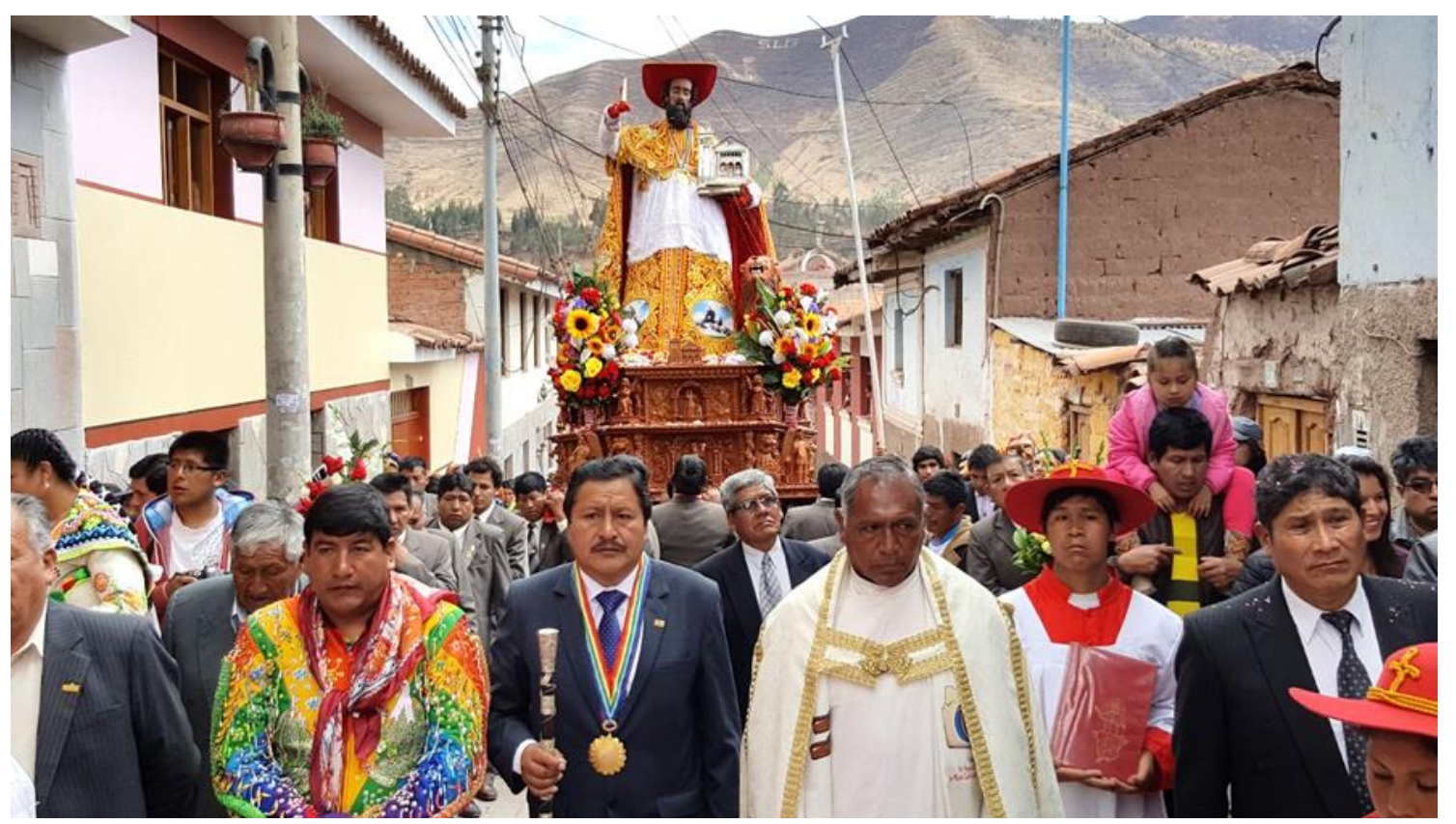

Figura 1: Procesión con autoridades gubernamentales y eclesiásticas. Fotografía: Luis Serrano Paucarmayta, 2018

b) Ritualidad y tradición cusqueña

Se basa en el conjunto de creencias de origen católico/andino, producto de un proceso de sustitución y síntesis cultural que ocurrió con la llegada de la cultura europea (Serrano Paucarmayta, 2018). Este proceso determinó un desarrollo cultural particular en nuestro medio social que aún puede observarse en las siguientes manifestaciones:

Materiales: Son parte del patrimonio de las órdenes religiosas católicas y devotos de las diferentes parroquias y distritos del Cusco —entre ellos se encuentran las imágenes religiosas elaboradas por artistas cusqueños y algunas traídas de Europa- las cuales tienen facciones propias del hombre andino. Asimismo, están los trajes, capas y adornos de las imágenes religiosas, producto de las donaciones y regalos de sus devotos desde la época colonial y las andas procesionales. Finalmente, la construcción y armado de los altares de espejo, constituye una tradición propia de las fiestas patronales cusqueñas.

Inmateriales: Son parte de la cultura viva de cada parroquia del Cusco, distinguimos:

- Estructuras sociales: Los sistemas de cargos o carguyuj (dignatario), son distintos tipos de redes sociales interpersonales que se forman en torno a una virgen o santo patrón para organizar su culto y festividad central. Su estructura está colmada de muchos elementos simbólicos tangibles (las demandas o solicitudes, las jurk'as, los estandartes, las bandas y detentes, etc.), e intangibles (los rituales de jurk'a, la jerarquía social y los roles en la fiesta, etc.). Los lazos de afectividad que se tejen en estas redes son de tipo social y generacional (Huayhuaca Villasante, 1985).

- Normas de comportamiento social: Una de las principales normas sociales en las fiestas patronales es la reciprocidad; creencia tradicional que implica la expectativa cultural de que la gente obtiene lo que merece (Gouldner, 1960). Roger Magazine, en un estudio de los pueblos mesoamericanos — que puede ser aplicado a la realidad latinoamericana—, afirma que lo más importante de la fiesta patronal es cómo esta se lleva a cabo; de manera más específica, "que se prepare entre todos". El punto clave no está en crear "el todo", sino en producir "el hacer" entre la mayor cantidad de gente posible (Magazine, 2012, pág. 119).

- Mitos y oralidad: La creencia popular de cada parroquia y distrito, conserva distintos mitos relacionados con sus vírgenes y santos patronos. Una de las particularidades de estos mitos es, que en su estructura se encuentran contextos y elementos nativos que transmiten estructuras y códigos sociales que revelan arquetipos propios de la cosmovisión andina, como el mito de San Cristóbal y Santa Ana con la chicha (Serrano Paucarmayta, 2018).

- Ceremonias y rituales: Además de los rituales propios del sistema de cargos, existen otros rituales como: el riqcharikuy, cochachikuy, el "despierto", la "bajada" del santo, el andapichakuy, los pututeros, etc.; los cuales son parte de la creencia católico/andina que tienen los devotos para con sus imágenes. 


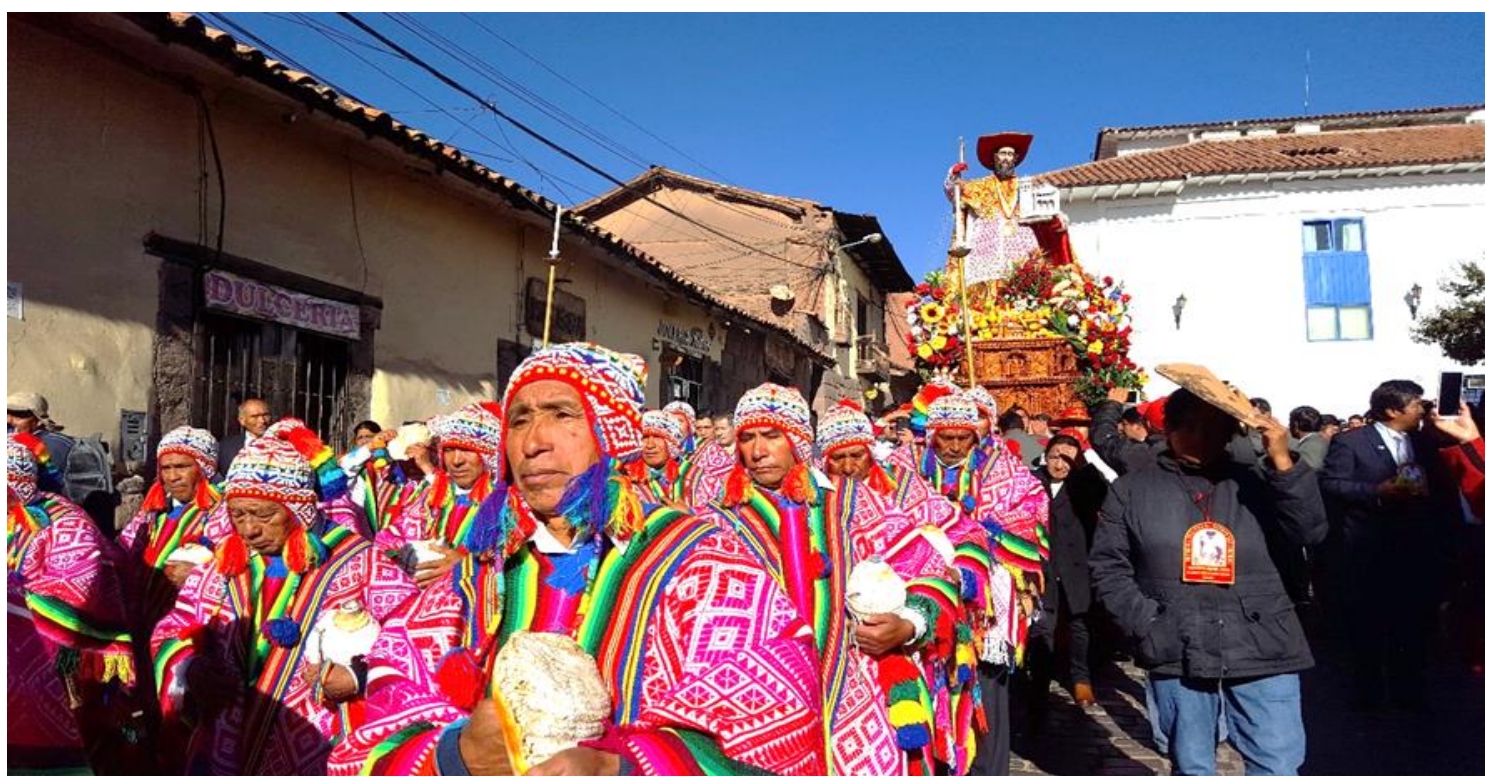

Figura 2: Pututeros del Patrón San Jerónimo. Fotografía: Luis Serrano Paucarmayta, 2018

c) Danzas típicas: Constituyen un tipo de representación social y una actividad muy difundida en los andes, que permitió restructurar el pensamiento andino al combinar expresiones simbólicas y religiosas - como forma de expresión de interacción cultural, religiosa y social-, la danza en las fiestas patronales permite convocar distintos grupos humanos afines en la ciudad en un determinado espacio y tiempo. Las principales danzas que se bailan en las 35 fiestas patronales del Cusco son: Cápac Colla, Cápac Negro, Cápac Chunchu, Contradanza, Mestiza Coyacha, Danzas del altiplano, Albazo, Auca Chileno, Cocasaru, etc.

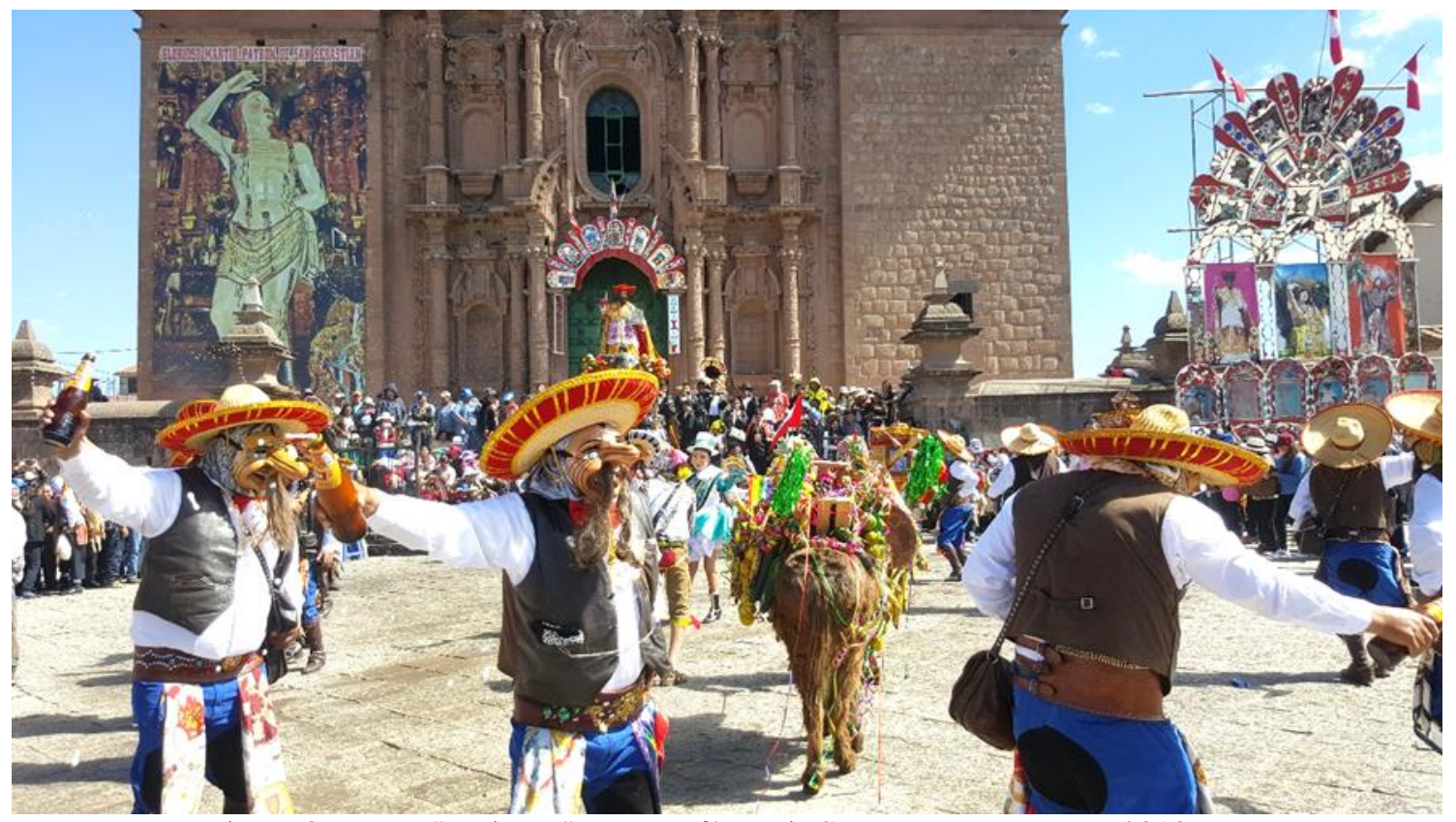

Figura 3: Danza "Majeños". Fotografía: Luis Serrano Paucarmayta, 2018

Rev. Yachay volumen (7) Número (1), enero-diciembre 2018 
d) Gastronomía típica: Al igual que la conformación de las creencias, la gastronomía típica cusqueña es el resultado de la fusión de ingredientes y formas de preparación de alimentos europeos y nativos. Una característica resaltante de la gastronomía cusqueña es: que algunos platos son rituales y propios de una determinada festividad durante el año. El potaje bandera que expresa esta noción de continuidad e interculturalidad en el Cusco es el chiriuchu, el cual es un plato emblemático de la fiesta del Corpus Christi y data de la época de los incas y la colonia (Huayhuaca Villasante, 1985).

Además, también encontramos los siguientes platos típicos en distintas festividades del Cusco: Qowe lawa, Almuerzo de Kuchiqara, Puchero, kapchi de zetas, chicharrones, chicha de jora, frutilladas, perachapchi, etc.; y dulces típicos como los guisados de frutas, las empanadas, condesas, los suspiros, el pan torta, pan costra (Qaran t'anta), los panes wawa y caballo.

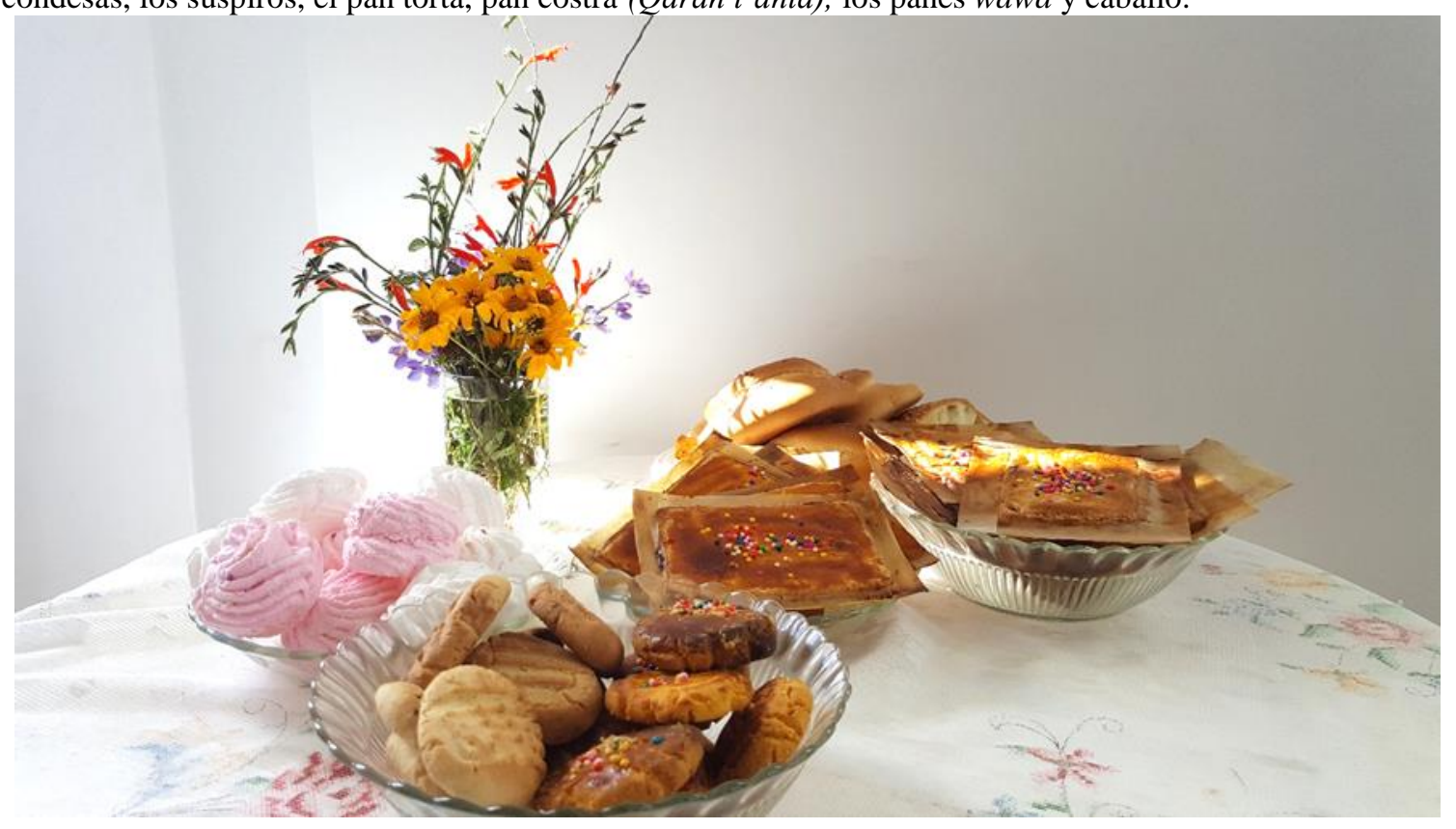

Figura 4: Dulces de Semana Santa. Fotografía: Luis Serrano Paucarmayta, 2018

La periodicidad de acuerdo al calendario festivo/religioso. Las dimensiones del patrimonio cultural inmaterial anteriormente mencionados forman parte de las 35 fiestas patronales más importantes del Cusco, y se encuentran dependiendo de la importancia de la festividad. Asimismo, hay fiestas tradicionales como los carnavales, la Semana Santa, Todos los Santos y el Santurantikuy, que presentan características particulares igualmente atractivas para el turismo.

El calendario católico/festivo de nuestra ciudad Capital Arqueológica de América, es muy variado puesto que, hay un promedio de dos a tres celebraciones mensuales. Desde el punto de vista turístico, esta característica de las fiestas patronales es una oportunidad para su diversificación y disponibilidad anual en el mercado turístico.

\section{Discusión}

A través de la observación participante en 35 fiestas patronales de la ciudad del Cusco y la contrastación con material documental, se registraron las siguientes manifestaciones culturales presentes en dichas festividades: los actos litúrgicos católicos mezclados con expresiones materiales e inmateriales de religiosidad popular cusqueña, las danzas y la gastronomía típica. De esta manera, se comprobó que existe continuidad cultural prehispánica tal como afirman Huayhuaca Villasante (1985) y Serrano Paucarmayta (2018).

La riqueza cultural, y particularidades que muestran cada una de las fiestas estudiadas nos demostraron su potencial turístico. De acuerdo a la ley peruana del patrimonio cultural inmaterial Ley n ${ }^{\circ} 28296$ (2017), y el «Manual para la formulación y evaluación del inventario de atractivos turísticos a nivel nacional» (2012) se categorizaron las 35 fiestas patronales observadas en la ciudad del Cusco. De esta forma, se comprobó que estas fiestas pueden ser incluidas en la oferta turística de la ciudad del Cusco. 
Toledo Verdugo (2014) reconoce como producto turístico de alto valor a los atractivos de la provincia ecuatoriana del Cañar, por presentar características indígenas y españolas mezcladas. Del mismo modo, mediante la observación, categorización y contrastación con estudios previos de las 35 fiestas patronales del Cusco, se pudo comprobar la gran riqueza de sus manifestaciones culturales, producto de la unión de elementos europeos y precolombinos, lo que las hacen atractivos potenciales turísticos de gran valor.

Se concuerda con la tesis de Urbina Chuyacama (2015), cuando dicho autor plantea el interés turístico por las vivencias, costumbres y tradiciones del hombre andino como un aporte positivo en la diversificación de la oferta turística. Sin embargo, se cree que no beneficia en nada a la oferta turística la promoción de una fiesta al año; por esta razón, se establece que uno de los principales aportes de la presente investigación es la integración de estas 35 fiestas anuales en la ciudad del Cusco, equitativamente distribuidas en el calendario festivo y con particularidades propias, que servirán para diversificar la oferta turística del turista estacional y también, como un eje motivacional y temporal para el turista que planifique con anticipación su visita al Cusco.

\section{Conclusiones}

Las fiestas patronales del Cusco, constituyen atractivos culturales inmateriales que son parte de la oferta turística de la ciudad del Cusco. A través de la integración de 35 eventos anuales en la ciudad del Cusco se diversifica la oferta turística del turista estacional y se establece también un eje motivacional y temporal para que el turista planifique con anticipación su visita al Cusco.

Las fiestas patronales del Cusco, permiten su incorporación a la oferta turística cultural de nuestra ciudad por tres razones fundamentales:

1) las expresiones culturales propias de cada grupo social o parroquia son muy variadas.

2) Son numerosas y están equitativamente distribuidas durante el calendario festivo cusqueño.

3) Los organizadores y participantes activos consideran beneficioso el turismo cultural en las fiestas patronales del Cusco, en tanto contribuya a la difusión de sus costumbres y creencias.

\section{Referencias bibliográficas}

(MINCETUR), M. d. (2017). Guía sobre declaratorias de expresiones del patrimonio cultural inmaterial. Lima: Ministerio de Cultura del Perú. Obtenido de http://administrativos.cultura.gob.pe/intranet/dpcn/anexos/Guia_2017.pdf

Cánepa Koch, G. (1988). Máscara, transformación e identidad en los andes: La fiesta de la Virgen del Carmen Paucartambo-Cuzco. Lima, Perú: PUCP - Fondo Editorial.

Chacón Cruz, S. R. (2014). Manifestaciones Folclóricas de la Provincia de Trujillo como factor que impulsa la diversificación de la actual Oferta Turística. (F. E. UNT, Ed.) Trujillo , Perú: Facultad de Ciencias Sociales Escuela Académica profesional de Turismo - Universidad Nacional de Trujillo.

Correo, R. (27 de noviembre de 2017). El 77.9\% de los peruanos son católicos. Obtenido de Diario Correo: https://diariocorreo.pe/edicion/lima/779-peruanos-son-catolicos-788465/),

De la Cadena, Marisol, Orin Starn. (2010). Indigeneidades contemporáneas: cultura, política y globalización. (I. d. Institut français d'études andines, Ed.) Lima, Perú: Instituto de Estudios Peruanos. doi: 10.4000/books.ifea.6218

Flores Ochoa, J. A. (1990). El Cusco: resistencia y continuidad. (C. d. Andinos, Ed.) Cusco, Perú: Qosqo .

Gouldner, A. (abril de 1960). The norm of reciprocity: A preliminary statement. American Sociological Review, 25(2), 161-178. doi: 10.2307 / 2092623

Hiernaux, D. (2002). Turismo e Imaginarios. En D. Hiernaux, N. Allen, \& L. van Duynen Montijin, Imaginarios Sociales y Turismo Sostenible (págs. 7-35). Costa Rica: Facultad Latinoamericana de Ciencias Sociales (FLACSO).

Huayhuaca Villasante, L. (1985). La festividad del Corpus Christi en el Cusco. Cusco, Perú: Talleres Gráficos P.L. Villanueva,.

Magazine, R. (2012). El otro como sujeto, la modernidad como conducto: La producción de subjetividades en un pueblo mesoamericano. Autor: Roger Magazine. En P. Pitarch, G. (. Orobitg, P. Pitarch, \& G. Orobitg (Edits.), Modernidades indígenas (págs. 115134). Madrid, España: Iberoamericana - Vervuert. 
Mallor, E., González-Gallarza Granizo, M., \& Fayos Gardó, T. (2013). ¿Qué es y cómo se mide el Turismo Cultural? Un estudio longitudinal con series temporales para el caso español. PASOS Revista de Turismo y Patrimonio Cultural Vol 11 N. ${ }^{\circ} 2$, 269284.

Martínez Cárdenas, R. (Ed.). (2013). Santuarios, fiestas patronales, peregrinaciones y turismo religioso. Guadalajara: Fundación Universitaria Andaluza Inca Garcilaso. Obtenido de http://www.eumed.net/libros-gratis/2013/1281/index.htm

MINCETUR. (2012). Manual para la formulación y evaluación del inventario de atractivos turísticos a nivel nacional. MINCETUR, Desarrollo de producto turístico. Lima: Helmen Perú SAC. Recuperado el 12 de octubre de 2018, de https://www.mincetur.gob.pe/wp-content/uploads/documentos/turismo/consultorias/directoriosManuales/Manual-FormulacionInventarioRecursosTuristicos-NivelNacional.pdf

Navarro, D. (2015). Recursos turísticos y atractivos turísticos: conceptualización, clasificación y valoración. Cuadernos de Turismo(35, enero-junio), 335-357. Obtenido de http://www.redalyc.org/pdf/398/39838701014.pdf

PROMPERÚ. (09 de Abril de 2018). Conociendo al turista que visitó CUSCO durante el año 2017. Obtenido de Comisión de la Promoción de Perú para la Exportación y el Turismo:

https://promperu.gob.pe/TurismoIN//Uploads/temp/Uploads_conociendoAlTurista_57_Turista\%20de\%20festividades\%20Cusc o\%202017\%20-\%20Receptivo.pdf //

Quintero Santos, J. L. (2004). Los impactos económicos, socioculturales y medioambientales del turismo y sus vinculos con el turismo sostenible. Anales del Museo de America 12, 263 - 274.

Serrano Paucarmayta, L. (2018). Los Hermanos y la Chicha: Reconstrucción simbólica de un mito fundacional inca y preinca en el culto popular a Santa Ana y San Cristóbal del Cusco. Revista Académica Kuntur - Universidad Andina Cusco, 1(2), 213-226.

Toledo Verdugo, Maria Caridad; Ullauri Donoso, Narcisa. (2014). Fiestas populares, una alternativa del turismo cultural en la provincia del Cañar. Universidad del Azuay, Facultad de Filosofía, Letras y Ciencias de la Educación. Cuenca - Ecuador: Facultad de filosofía, letras y ciencias de la educación. Escuela de Turismo. Recuperado el 5 de mayo de 2018, de http://dspace.uazuay.edu.ec/handle/datos/3754

Urbina Chuyacama, R. E. (2015). Incorporación de la festividad del Señor de Torrechayoc como atractivo turístico en el circuito Valle Sagrado. (UAC, Ed.) Cusco, Perú: Facultad de Ciencias Sociales y Educación - Escuela profesional de Turismo. Universidad Andina del Cusco. 